\title{
ANALISIS INVESTASI USAHATANI KEDELAI VARIETAS TANGGAMUS DI KABUPATEN GORONTALO (Suatu Pendekatan Analisis Manfaat-Biaya)
}

\author{
Zulkifli Mantau
}

\begin{abstract}
The increase of soybeans world price was causing of a domino effect for the Indonesian's soybeans. Meanwhile, soybean productivity at the farm level is still low ( $1.3 \mathrm{t} / \mathrm{ha}$ ) with a range from 0.6 to $2.0 \mathrm{t} /$ ha. In additional, the production technology can able to result of 1.7 to $3.2 \mathrm{t} / \mathrm{ha}$. To solve these problems, It needs to planted the soybean that have a high productivity and efficient technically and economically. The aims of this research are to find the investement feasibility of soybean farming (Tanggamus var.) at Puncak Village, Gorontalo District with benefit cost analysis approach (3 years projection). This research conducted at Puncak Village, Pulubala sub district, Gorontalo District. The datas was a primary observation data in the field, especially the data of soybeans farming activities for 2 seasons (1 year). Analysis method use a benefit cost analysis. The analysis use a financial price (actual price) in the cost factors. The result showed that Net Present Value (NPV) (12\%) Rp 10269 643, Internal Rate of Return (IRR) 97.21\%, Net Benefit Cost ratio (Net B/C) 2.64 and Payback periodh (PBP) 9 months or 0.7 year or 2 planted seasons.
\end{abstract}

Keywords : Benefit-cost analysis, soybean var. Tanggamus

\begin{abstract}
ABSTRAK
Permasalahan naiknya harga kedelai dunia, menyebabkan efek domino bagi dunia kedelai di Indonesia.Sementara, produktivitas pertanaman kedelai di tingkat petani masih rendah ( $1,3 \mathrm{t} / \mathrm{ha})$ dengan kisaran 0,6 - 2,0 t/ha, padahal teknologi produksi yang tersedia mampu menghasilkan 1,7 - 3,2 t/ha. Untuk mengatasi permasalahan tersebut diatas perlu dilakukan terobosan dalam memproduksi kedelai yang mampu memberikan produktivitas tinggi dengan proses produksi yang efisien dan berkelanjutan. Tujuan penelitian ini adalah untuk mengetahui kelayakan investasi usahatani kedelai varietas Tanggamus di Desa Puncak Kecamatan Pulubala Kab. Gorontalo melalui pendekatan analisis manfaat-biaya dengan proyeksi periode usaha selama 3 tahun. Penelitian dilaksanakan di Desa Puncak Kecamatan Pulubala Kabupaten Gorontalo Provinsi Gorontalo. Data-data merupakan data primer pengamatan lapangan selama dua musim tanam (1 tahun) 2013. Analisis data menggunakan metode analisis manfaat biaya (benefit-cost analysis). Pendekatan harga pada faktor biaya menggunakan pendekatan harga aktual (secara finansial) selama satu tahun periode usaha (2 musim tanam). Hasil analisis kelayakan usaha selama proyeksi 3 tahun usaha adalah sebagai berikut Net Present Value (NPV) (12\%) Rp 10269643 , Internal Rate of Return (IRR) 97.21\%, Net Benefit Cost ratio (Net B/C) 2.64 dan Payback periodh (PBP) selama 9 bulan atau 0.7 tahun atau 2 musim tanam.
\end{abstract}

Kata kunci : Analisis manfaat-biaya, kedelai varietas Tanggamus 


\section{PENDAHULUAN}

Sebagai bagian dari revitalisasi pembangunan pertanian, pemerintah Republik Indonesia telah bertekad untuk meningkatkan produktivitas pangan nasional, khususnya kedelai melalui program swasembada pangan nasional padi, jagung, kedelai (PAJALE). Program ini harus didukung oleh semua pihak yang terkait, dalam proses produksinya. Pengalaman selama ini menunjukkan bahwa tingkat produksi nasional lebih ditentukan oleh areal tanam dari pada tingkat produktivitas. Namun demikian, peluang peningkatan produksi melalui perbaikan teknologi masih terbuka lebar. Dilain pihak secara umum minat petani untuk mengembangkan kedelai masih rendah jika dibandingkan komoditas pangan lain seperti padi, jagung, dan ubi kayu, karena pendapatan yang diperoleh dari usahatani kedelai masih tergolong rendah sebagai akibat dari faktor harga jual yang tidak menentu.

Permasalahan naiknya harga kedelai dunia, menyebabkan efek domino bagi dunia kedelai di Indonesia. Padahal kedelai di Indonesia hampir 70\% masih impor. Sampai tahun 2010 impor kedelai Indonesia mencapai 30 ribu ton dan sebagian besar untuk pemenuhan kebutuhan perusahaan tahu dan tempe. Sedangkan produktivitas pertanaman kedelai di tingkat petani masih rendah ( $1.3 \mathrm{t} / \mathrm{ha}$ ) dengan kisaran $0.6-2.0$ t/ha, padahal teknologi produksi yang tersedia mampu menghasilkan 1.7 - $3.2 \mathrm{t} / \mathrm{ha}$ (BPTP NTB, 2010).

Untuk mengatasi permasalahan tersebut diatas perlu dilakukan terobosan dalam memproduksi kedelai yang mampu memberikan produktivitas tinggi dengan proses produksi yang efisien dan berkelanjutan. Namun disadari bahwa peningkatan produksi saja tidak cukup jika tidak dibarengi dengan perbaikan harga jual kedelai di tingkat petani. Hal ini sangat penting karena walaupun produksi tinggi namun harga pasar tidak menguntungkan, maka jangan salahkan petani jika semakin enggan menanam kedelai. Untuk itu perlu dilakukan kajian mengenai proyeksi kelayakan investasi usahatani kedelai dalam jangka panjang, apakah memang dapat mendatangkan keuntungan bagi petani secara berkelanjutan ataukah justru mendatangkan kerugian. Sehingga informasi dari hasil penelitian dapat menjadi motivasi bagi petani selaku pelaku utama usahatani kedelai. Disamping dapat menjadi acuan kebijakan pemerintah dalam merumuskan harga pembelian pemerintah yang bisa menguntungkan petani kedelai.

Tujuan penelitian ini adalah untuk mengetahui kelayakan investasi usahatani kedelai varietas Tanggamus di Desa Puncak Kecamatan Pulubala Kab. Gorontalo melalui pendekatan analisis manfaat-biaya dengan proyeksi periode usaha selama 3 tahun.

\section{METODE PENELITIAN}

Tempat dan Waktu Penelitian

Penelitian dilaksanakan di Desa Puncak Kecamatan Pulubala Kabupaten Gorontalo Provinsi Gorontalo. Waktu pelaksanaan selama dua musim tanam kedelai (1 tahun) 2013 dan selanjutnya diproyeksi selama 3 tahun periode usaha.

\section{Jenis dan Sumber Data}

Data-data merupakan data primer pengamatan lapangan selama dua musim tanam (1 tahun) 2013. Selanjutnya data-data tersebut dianalisis dan diproyeksi selama 3 (tiga) tahun umur usaha. Data diambil pada usahatani kedelai dengan luasan areal 3 ha yang dikelola oleh 3 orang petani.

\section{Metode Analisis}

Analisis data menggunakan metode analisis manfaat biaya (benefit-cost analysis). Pendekatan harga pada faktor biaya menggunakan pendekatan harga aktual (secara finansial) selama satu tahun periode usaha (2 musim tanam).

Selanjutnya dianalisis pula proyeksi usaha selama 3 tahun (forecasting). Sehingga dapat diperkirakan kelayakan usahatani kedelai varietas Tanggamus ini dalam jangka panjang. Adapun parameter kelayakan usaha adalah net profit, BC ratio (BCR), Payback Period (PBP), Break Even Point (BEP) harga dan produksi, Internal Rate Return (IRR) dan Return of Investment (ROI).

Menurut Gittinger (1986) tujuan utama analisis finansial dalam usaha pertanian adalah untuk menentukan berapa banyak keluarga petani yang menggantungkan kehidupan mereka kepada 
usaha pertanian tersebut. Selanjutnya dikemukakan bahwa analis akan merasa perlu untuk membuat proyeksi mengenai anggaran yang akan mengestimasi penerimaan dan pengeluaran bruto pada masa-masa yang akan datang setiap tahun, termasuk biaya-biaya yang berhubungan dengan produksi dan pembayaranpembayaran kredit yang harus dikeluarkan oleh rumah tangga petani, agar dapat menentukan berapa besar pendapatan yang diterima oleh rumah tangga tani sebagai balas jasa tenaga kerja, keahlian manajemen, dan modal mereka.

Beberapa kriteria dalam menilai kelayakan suatu usaha yang paling umum digunakan adalah Net Present Value (NPV), Internal Rate of Return (IRR), Net Benefit Cost Ratio (Net B/C Ratio).

Net Present Value (NPV) merupakan manfaat bersih yang diterima selama umur proyek pada tingkat diskonto tertentu. NPV dapat dirumuskan sebagai berikut:

$$
N P V=\sum_{t=0}^{n} \frac{B t-C t}{(1+i)^{t}}
$$

Dimana :

$$
\begin{aligned}
& \mathrm{Bt} \quad=\text { Manfaat pada tahun ke } \mathrm{t} \\
& \mathrm{Ct} \quad=\text { Biaya pada tahun ke } \mathrm{t} \\
& 1 /(1+\mathrm{i})^{\mathrm{t}}=\text { Discount factor } \\
& \mathrm{t} \quad=\text { tahun }(1,2,3, \ldots \ldots . . \mathrm{n}) \\
& \mathrm{n} \quad=\text { Periode usaha }
\end{aligned}
$$

Ukuran ini bertujuan untuk mengurutkan alternatif yang dipilih karena adanya kendala biaya modal, dimana proyek ini memberikan NPV biaya yang sama atau NPV penerimaan yang kurang lebih sama setiap tahun. Proyek dinyatakan layak atau bermanfaat jika NPV lebih besar dari 0. Jika NPV sama dengan 0, berarti biaya dapat dikembalikan persis sama besar oleh proyek. Pada kondisi ini proyek tidak untung dan tidak rugi. NPV lebih kecil dari nol, proyek tidak dapat menghasilkan senilai biaya yang dipergunakan dan ini berarti bahwa proyek tersebut tidak layak dilakukan (Gray et.al, 1992).

\section{Internal Rate of Return (IRR)} menunjukkan rata-rata keuntungan internal tahunan perusahaan yang melaksanakan investasi dan dinyatakan dalam persen. IRR adalah tingkat suku bunga yang membuat nilai NPV proyek sama dengan nol. IRR secara matematis dapat dirumuskan sebagai berikut:

$$
I R R=i_{1}+\frac{N P V_{1}}{N P V_{1}-N P V_{2}}\left(i_{1}-i_{2}\right)
$$

Dimana:

$$
\mathrm{i}_{1} \quad=\text { tingkat diskonto yang }
$$
menghasilkan NPV positif

$\mathrm{i}_{2} \quad=$ tingkat diskonto yang menghasilkan NPV negatif

$$
\mathrm{NPV}_{1}=\mathrm{NPV} \text { positif }
$$$$
\mathrm{NPV}_{2}=\mathrm{NPV} \text { negatif }
$$

Investasi dikatakan layak jika IRR lebih besar dari tingkat diskonto, sedangkan jika IRR lebih kecil dari tingkat diskonto maka proyek tersebut tidak layak dilaksanakan. Tingkat IRR mencerminkan tingkat bunga maksimal yang dapat dibayar oleh proyek untuk sumber daya yang digunakan. Suatu investasi dinyatakan layak jika IRR lebih besar dari tingkat bunga yang berlaku.

Net Benefit Cost Ratio (Net B/C Ratio) adalah besarnya manfaat tambahan pada setiap tambahan biaya sebesar satu satuan. Net B/C adalah merupakan perbandingan antara nilai sekarang (present value) dari net benefit yang positif dengan net benefit yang negatif. Net B/C ratio secara matematis dapat dirumuskan sebagai berikut:

$$
N e t B / C=\sum_{t=1}^{n} \frac{B t}{(1+i)^{t}} / \sum_{t=1}^{n} \frac{C t}{(1+i)^{t}}
$$

Dimana:

$$
\begin{array}{ll}
\mathrm{Bt} & =\text { Manfaat pada tahun ke } \mathrm{t} \\
\mathrm{Ct} & =\text { Biaya pada tahun ke } \mathrm{t} \\
1 /(1+\mathrm{i}) & =\text { Discount factor } \\
\mathrm{n} & =\text { Periode usaha }
\end{array}
$$

Usahatani tersebut dikatakan layak bila NBCR lebih besar dari satu (Gray et al, 1992). 
Tabel 1. Biaya Investasi Usahatani Kedelai var.Tanggamus di Desa Puncak (2013)

\begin{tabular}{|c|c|c|c|c|c|c|c|c|}
\hline No & Komponen Biaya & Satuan & $\begin{array}{c}\text { Jml } \\
\text { Fisik }\end{array}$ & $\begin{array}{c}\text { Harga } \\
\text { per Satuan } \\
\text { Rp } \\
\end{array}$ & $\begin{array}{c}\text { Jumlah } \\
\text { Biaya } \\
\text { Rp } \\
\end{array}$ & $\begin{array}{c}\text { Umur } \\
\text { Ekonomis } \\
\text { (tahun) } \\
\end{array}$ & $\begin{array}{c}\text { Nilai } \\
\text { Penyusutan } \\
\text { Rp } \\
\end{array}$ & $\begin{array}{c}\text { Nilai } \\
\text { Sisa Proyek } \\
\text { Rp }\end{array}$ \\
\hline \multirow[t]{7}{*}{1} & Alat produksi & & & & & & & \\
\hline & a. Timbangan & unit & 1 & 400000 & 400000 & 3 & 133333 & 133333 \\
\hline & b. Sabit ukuran 27 & unit & 8 & 200000 & 1600000 & 3 & 533333 & 533333 \\
\hline & \multirow{2}{*}{$\begin{array}{l}\text { c. Cangkul } \\
\text { d. Alat bajak }\end{array}$} & unit & 3 & 200000 & 600000 & 3 & 200000 & 200000 \\
\hline & & unit & 1 & 750000 & 750000 & 5 & 150000 & 150000 \\
\hline & e. Keranjang panen & unit & 4 & 175000 & 700000 & 3 & 233333 & 233333 \\
\hline & f. Karung $80 \mathrm{~kg}$ & unit & 50 & 6000 & 300000 & 1 & 300000 & 300000 \\
\hline \multirow{5}{*}{2} & & & & & & & & \\
\hline & Peralatan lainnya & & & & & & & \\
\hline & c. Gerobak dorong & unit & 3 & 500000 & 1500000 & 5 & 300000 & \\
\hline & d. Nampan/nyiru & unit & 10 & 40000 & 400000 & 3 & 133333 & \\
\hline & Jumlah & & & & 6250000 & & 1983333 & 1550000 \\
\hline
\end{tabular}

Sumber: Olahan data primer (2013)

\section{HASIL DAN PEMBAHASAN}

Menurut Choliq, et al (1999) biaya usaha/ proyek adalah seluruh biaya yang dikeluarkan guna mendatangkan penghasilan (return) pada masa yang akan datang. Selanjutnya dikemukakan pula bahwa biaya proyek pada dasarnya diklasifikasikan atas biaya investasi dan biaya operasional, dimana penjelasannya sebagai berikut:

1. Biaya investasi adalah seluruh biaya yang dikeluarkan mulai proyek tersebut dilaksanakan sampai proyek tersebut mulai berjalan (beroperasi). Biaya investasi misalnya pendirian bangunan pabrik, pembelian mesin dan peralatannya, tenaga kerja yang berhubungan dengan investasi dan sebagainya.

2. Biaya operasional adalah seluruh biaya yang dikeluarkan karena proses produksi berlangsung dan secara rutin biaya ini harus dikeluarkn. Biaya operasional misalnya pembelian bahan baku, biaya listrik dan air, bahan bakar dan sebagainya.

Identifikasi biaya usahatani kedelai var.Tanggamus terdiri dari proses budidaya mulai dari persiapan lokasi (pengolahan tanah sempurna), benih kedelai, pemeliharaan sampai pada panen dan pemasaran. Arus biaya dari pengusahaan kedelai ini terdiri dari biaya investasi yang dikeluarkan sebelum memulai usaha dan biaya operasional yang dikeluarkan selama melakukan kegiatan produksi. Rincian biaya investasi usahatani kedelai var.Tanggamus seperti terlihat pada Tabel 1. Sedangkan pada Tabel 2 menyajikan data biaya produksi dan hasil produksi serta pendapatan kotor (hasil penjualan) dari kedelai varietas Tanggamus di Desa Puncak.

Hasil panen tersebut merupakan hasil riil rata-rata per ha dari kedelai varietas Tanggamus yang dibudidayakan di lokasi Demfarm Desa Puncak kec. Pulubala. Hasil ini 2 kali lebih tinggi dibanding potensi hasil rata-rata berdasarkan deskripsi varietas yang hanya $1.22 \mathrm{t} / \mathrm{ha}$ (Pusat Perpustakaan Badan Litbang Pertanian, www.pustaka.litbang.go.id diakses tanggal 21/11/2012).

Hasil penelitian Tahir, et al. (2010) mengenai faktor-faktor yang mempengaruhi efisiensi produksi usahatani kedelai, menemukan bahwa secara teknis faktor-faktor yang mempengaruhi peningkatan produksi kedelai adalah tingkat pengalaman petani, jumlah angkatan kerja dalam keluarga, jumlah pupuk urea, jumlah pupuk $\mathrm{KCl}$, jumlah pupuk organik, dummy status kepemilikan lahan sistem bagi hasil, dummy varietas kedelai (varietas unggul), dummy jarak tanam (40 x $15 \mathrm{~cm}$ dan $40 \times 10 \mathrm{~cm})$, dan dummy tipe lahan. 
Tabel 2. Biaya produksi, Produksi riil rata-rata dan pendapatan kotor usahatani kedelai di Desa Puncak (2013)

\begin{tabular}{ccccccc}
\hline Produk & $\begin{array}{c}\text { Volume } \\
(\mathrm{kg} / \mathrm{ha})\end{array}$ & $\begin{array}{c}\text { Biaya } \\
\text { Variabel }(1 \\
\text { Tahun }) \\
(\mathrm{Rp})\end{array}$ & $\begin{array}{c}\text { Biaya } \\
\text { Tetap }(1 \\
\text { Tahun }) \\
(\mathrm{Rp})\end{array}$ & $\begin{array}{c}\text { Harga } \\
\left.\text { Jual }^{*}\right) \\
(\mathrm{Rp})\end{array}$ & $\begin{array}{c}\text { Penjualan } \\
\text { Per Musim } \\
(\mathrm{Rp})\end{array}$ & $\begin{array}{c}\text { Penjulan } \\
1 \text { Tahun } \\
(\mathrm{Rp})\end{array}$ \\
\hline kedelai & 2396 & 69500000 & $\begin{array}{c}95200 \\
000\end{array}$ & 6000 & 14377600 & 172531200 \\
konsumsi & & & & & $\mathbf{1 4 3 7 7 6 0 0}$ & $\mathbf{1 7 2 5 3 1 2 0 0}$ \\
\hline TOTAL & & & &
\end{tabular}

Ket. *) Harga jual Bulan Agustus 2013; Sumber : Olahan data primer (2013)

Ketiga input produksi (pupuk) tersebut masih bisa dinaikkan jumlahnya untuk meningkatkan produksi. Sedangkan secara ekonomis, pencapaian efisiensi dimungkinkan dengan mengurangi penggunaan tenaga kerja upahan (luar keluarga) untuk menambah pendapatan, serta mengurangi penggunaan benih kedelai, tenaga kerja upahan, dan luas lahan garapan untuk meningkatkan keuntungan usahatani kedelai. Jika dihubungkan dengan penelitian ini, maka faktor tenaga kerja upahan (luar keluarga) merupakan faktor yang sangat berpengaruh pada peningkatan biaya produksi dan berdampak pada perolehan keuntungan usahatani kedelai tersebut.

Selanjutnya secara teoritis Doll and Orazem (1992) mengemukakan bahwa dalam ekonomi produksi, efisiensi ekonomi dapat dicapai jika dipenuhi dua kriteria, yaitu :

1. Syarat keharusan (necessary condition), yaitu suatu kondisi dengan produksi dalam jumlah yang sama tidak mungkin dihasilkan dengan menggunakan sejumlah input yang lebih sedikit dan produksi dalam jumlah yang lebih besar tidak mungkin dihasilkan dengan menggunakan jumlah input yang sama.

2. Syarat kecukupan (sufficiency condition), yaitu syarat yang diperlukan untuk menentukan letak efisiensi ekonomi yang terdapat pada daerah rasional, karena dengan hanya mengetahui fungsi produksi saja maka letak efisiensi ekonomi yang terdapat pada daerah rasional tidak bisa ditentukan. Untuk menentukan letak efisiensi ekonomi diperlukan suatu alat yang merupakan indikator pilihan yaitu berupa input dan harganya.
Soekartawi (1993) dan Nicholson (2004) mengemukakan bahwa dalam terminologi ilmu ekonomi, mengemukakan bahwa efisien dapat digolongkan menjadi 3 (tiga) macam, yaitu : efisiensi teknis, efisiensi alokatif (efisiensi harga ) dan efisiensi ekonomi. Seorang petani secara teknis dikatakan lebih efisien (efisiensi teknis) dibandingkan dengan yang lain bila petani itu dapat berproduksi lebih tinggi secara fisik dengan rnenggunakan faktor produksi yang sama. Sedangkan efisiensi harga dapat dicapai oleh seorang petani bila ia mampu memaksimumkan keuntungan (mampu menyamakan nilai marginal produk setiap faktor produksi variabel dengan harganya). Efisiensi ekonomi terjadi bila efisiensi harga dan efisiensi teknis terjadi (Yotopoulos dan Lau, dalam Kusumawardani, 2002; Susantun, 2000).

Dalam kasus penelitian ini maka para petani yang mengelola lahan kedelai seluas 3 ha tersebut secara tidak langsung telah menerapkan konsep-konsep dari teori produksi tersebut. Misalnya mereka menerapkan konsep gotong royong dalam hal pengolahan tanah. Masingmasing petani memiliki 1 unit bajak sapi dan ketiga unit bajak tersebut secara bergantian melakukan pengolahan tanah pada areal lahan kedelai tersebut. Sehingga secara teknis para petani tersebut telah melakukan efisiensi, demikian pula dengan efisiensi harga karena biaya yang keluar pada masing-masing petani dapat ditekan. Secara langsung efisiensi ekonomi pun dapat tercapai.

Untuk lebih rinci mengenai tingkat rugilaba usahatani kedelai seperti tersaji pada Tabel 3. 
Tabel 3. Proyeksi Rugi/Laba Usahatani Kedelai di Desa Puncak selama 3 tahun periode usaha (Rp)

\begin{tabular}{|c|c|c|c|c|}
\hline \multirow{2}{*}{ No } & \multirow{2}{*}{ Uraian } & \multicolumn{3}{|c|}{ Tahun } \\
\hline & & 1 & 2 & 3 \\
\hline \multirow[t]{2}{*}{ A } & Penerimaan & & & \\
\hline & Total Penerimaan & 172531200 & 172531200 & 172531200 \\
\hline \multirow[t]{7}{*}{$\mathrm{B}$} & Pengeluaran & & & \\
\hline & i. Biaya Variabel & 69500000 & 69500000 & 69500000 \\
\hline & ii. Biaya Tetap & 95200000 & 95200000 & 95200000 \\
\hline & iii. Depresiasi & 1983333 & 1983333 & 1983333 \\
\hline & $\begin{array}{l}\text { iv. Angsuran Bunga } \\
\text { v. Biaya }\end{array}$ & 1014186 & 615162 & 216138 \\
\hline & Pemasaran/Distribusi & - & - & - \\
\hline & Total Pengeluaran & 167697519 & 167298495 & 166899471 \\
\hline $\mathrm{C}$ & R/L Sebelum Pajak & 4833681 & 5232705 & 5631729 \\
\hline $\mathrm{F}$ & Pajak $(15 \%)$ & 725052 & 784906 & 844759 \\
\hline G & Laba Setelah Pajak & 4108629 & 4447799 & 4786969 \\
\hline $\mathrm{H}$ & Profit on Sales & $2.38 \%$ & $2.58 \%$ & $2.77 \%$ \\
\hline \multirow[t]{2}{*}{ I } & BEP: harga (Rupiah) & 164436946 & 163768759 & 163100572 \\
\hline & produksi $(\mathrm{kg} / \mathrm{ha})$ & 205546 & 204711 & 203876 \\
\hline
\end{tabular}

Sumber : Olahan data primer (2013)

Berdasarkan Tabel 3 terlihat bahwa perolehan laba (setelah dipotong pajak) pada tahun kedua usahatani kedelai mencapai $92 \%$. Nilai ini meningkat menjadi $93 \%$ saat akhir panen pada tahun ketiga. Hal ini menunjukkan untuk periode usaha jangka panjang (long run) akan terjadi peningkatan perolehan laba yang cukup tinggi setiap tahunnya, atau dengan kata lain, terdapat trend peningkatan laba sebesar $50 \%$ setiap tiga tahunan. Demikian halnya yang terjadi dengan tingkat keuntungan penjualan (Profit on sales), terjadi peningkatan pada periode usaha 3 tahunan. Nilai profit on sales tersebut (Tabel 3) mengandung arti bahwa terdapat keuntungan sebesar $2.38 \%$ yang bisa diperoleh pada saat penjualan hasil per musim pada tahun pertama usaha dan seterusnya.

Hasil Break even point (BEP) produksi $(\mathrm{kg})$ memberikan gambaran bahwa selama tiga tahun operasional usaha, produksi kedelai tanggamus yang harus dicapai agar supaya usaha tersebut mencapai titik impasnya senantiasa mengalami penurunan dari tahun ke tahun. Demikian pula dengan BEP penjualan (Rp) yang harus diperoleh proyek tersebut agar mencapai titik impasnya. Hal ini mengindikasikan usaha ini bisa menghasilkan keuntungan yang lebih jika dilakukan dalam jangka waktu yang lebih panjang.

Analisis arus kas (cash flow) sangat penting untuk memperkirakan (prediksi) tingkat keuntungan dan kerugian yang akan diperoleh sebelum memulai suatu kegiatan usaha. Disamping itu sangat penting pula untuk menghitung tingkat keuntungan pada satu periode usaha jangka panjang (misalkan 3 tahunan, 5 tahunan dan 10 tahunan). Dengan adanya analisis cash flow pelaku usaha atau petani dapat mengetahui secara tepat berapa tingkat keuntungan dan kerugian dari usahatani yang dilakukan, sehingga dapat mempertimbangkan apakah usaha ini dilanjutkan dalam periode yang lebih panjang ataukah hanya berhenti pada satu periode usaha. 
Tabel 4. Proyeksi Arus Kas (cash flow) Usahatani Kedelai di Desa Puncak, proyeksi selama 3 tahun periode usaha (Rupiah)

\begin{tabular}{|c|c|c|c|c|c|}
\hline \multirow{2}{*}{ No } & \multirow{2}{*}{ Uraian } & \multicolumn{4}{|c|}{ Tahun } \\
\hline & & $\mathbf{0}$ & 1 & 2 & 3 \\
\hline \multirow[t]{12}{*}{$\mathbf{A}$} & Arus Masuk & & & & \\
\hline & 1. Total Penjualan & & 172531200 & 172531200 & 172531200 \\
\hline & 2. Kredit & & & & \\
\hline & a. Investasi & 1875000 & & & \\
\hline & b. Modal Kerja & & 7905000 & & \\
\hline & 3. Modal Sendiri & & & & \\
\hline & a. Investasi & 4375000 & & & \\
\hline & b. Modal Kerja & & 18445000 & & \\
\hline & & & & & 1016 \\
\hline & 4. Nilai Sisa Proyek & & & & 667 \\
\hline & Total Arus Masuk & 6250000 & 198881200 & 172531200 & 173547867 \\
\hline & $\begin{array}{l}\text { Arus Masuk unt } \\
\text { Menghitung IRR }\end{array}$ & - & 172531200 & 172531200 & 173547867 \\
\hline \multirow[t]{11}{*}{$\mathbf{B}$} & Arus Keluar & & & & \\
\hline & 1. Biaya Investasi & 6250000 & - & - & 1600000 \\
\hline & 2. Biaya Variabel & & 69500000 & 69500000 & 69500000 \\
\hline & 3. Biaya Tetap & & 95200000 & 95200000 & 95200000 \\
\hline & 4. Angsuran Pokok & & 3260000 & 3260000 & 3260000 \\
\hline & & & & & 216 \\
\hline & 5. Angsuran Bunga & & 1014186 & 615162 & 138 \\
\hline & & & 725 & 784 & 844 \\
\hline & 6. Pajak & & 052 & 906 & 759 \\
\hline & Total Arus Keluar & 6250000 & 169699238 & 169360068 & 170620897 \\
\hline & $\begin{array}{l}\text { Arus Keluar unt } \\
\text { Menghitung IRR }\end{array}$ & 6250000 & 165425052 & 165484906 & 167144759 \\
\hline \multirow[t]{3}{*}{$\mathbf{C}$} & Arus Bersih (NCF) & - & 29181962 & 3171132 & 2926969 \\
\hline & CASH FLOW & & & & \\
\hline & UNTUK & & & & \\
\hline \multirow[t]{3}{*}{ D } & MENGHITUNG IRR & $(6250000)$ & 7106148 & 7046294 & 6403107 \\
\hline & Discount Factor (12\%) & 1.0000 & 0.8929 & 0.7972 & 0.7118 \\
\hline & Present Value & $\left(\begin{array}{l}6250 \\
000\end{array}\right)$ & 6344775 & 5617263 & 4557605 \\
\hline $\mathbf{E}$ & CUMMULATIVE & $(6250000)$ & 94775 & 5712038 & 10269643 \\
\hline \multirow{8}{*}{$\mathbf{F}$} & ANALISIS & & & & \\
\hline & KELAYAKAN & & & & \\
\hline & USAHA & & & & \\
\hline & NPV $(12 \%)$ & Rp 10269643 & & & \\
\hline & IRR & $97.21 \%$ & & & \\
\hline & Net B/C & 2.64 & & & \\
\hline & PBP & 0.7 & tahun & & \\
\hline & & 9.0 & Bulan (2 MT) & & \\
\hline
\end{tabular}

Sumber : Olahan data primer (2013) 
Dalam penelitian ini dilakukan analisis cash flow dengan periode usaha 3 tahun. Dasar pertimbangannya karena kedelai merupakan tanaman semusim (berumur pendek), sehingga diharapkan benefit (manfaat) dari biaya dan modal yang dikeluarkan dapat dirasakan oleh petani dalam kurun waktu yang pendek pula. Benefit dalam hal ini seperti rasio pengembalian modal, kelayakan usaha serta nilai atau besaran keuntungan yang dapat dirasakan oleh petani selama periode usaha tersebut (Tabel 4).

Nilai NPV pada Tabel 4 tersebut menjelaskan bahwa penanaman investasi usahatani kedelai Tanggamus akan memberikan keuntungan sebesar Rp. 10 269643 selama 3 tahun.

Hasil IRR (Internal Rate of Return) menunjukkan bahwa usahatani kedelai tersebut layak dilaksanakan karena memiliki ratio pengembalian internal yang lebih besar dari suku bunga diskonto (12\%). IRR merupakan tingkat bunga maksimum yang dapat dibayar oleh proyek atau suatu usaha untuk sumberdaya yang digunakan karena usahatersebut membutuhkan dana lagi untuk biaya-biaya operasional, investasi dan proyek baru sampai pada tingkat pengembalian modal.

Nilai B/C pada Tabel 4 tersebut menjelaskan bahwa untuk setiap nilai sekarang dari pengeluaran 1 rupiah akan memberikan penerimaan sebesar $\mathrm{Rp}$. 2.64 dengan lama pengembalian modal sebesar 0.7 tahun atau hanya 9.0 bulan atau 2 musim tanam. Nilai $\mathrm{B} / \mathrm{C}>1$ menunjukkan bahwa usaha ini layak untuk dilakukan.

Tabel 5 memberikan gambaran mengenai rasio keuangan usahatani kedelai di Desa Puncak. Rasio keuangan terbagi atas rasio likuiditas, rasio solvabilitas dan rasio profitabilitas.

Rasio likuiditas menunjukkan kemampuan perusahaan atau usahatani dalam memenuhi kewajibannya dengan menggunakan kas dari aktivitas operasi serta digunakan untuk menilai tingkat likuiditas suatu usaha atau perusahaan (Fajarwati, 2007). Sedangkan rasio lancar (current ratio) sendiri sangat berguna untuk mengukur kemampuan perusahaan dalam melunasi kewajiban-kewajiban jangka pendeknya, dimana dapat diketahui sampai seberapa jauh sebenarnya jumlah aktiva lancar perusahaan dapat menjamin hutang lancarnya. Semakin tinggi rasio berarti semakin terjamin hutang-hutang perusahaan kepada kreditor. Rasio solvabilitas khususnya debt to asset ratio menjelaskan bahwa semakin tinggi rasio ini semakin tinggi resiko keuangan perusahaan. Dalam batas tertentu bank akan sulit untuk mengabulkan permohonan kredit. Hanya saja setiap bank batasnya berbeda.

Tabel 5 menjelaskan bahwa sampai tahun ketiga rasio tersebut menurun, artinya bahwa usahatani kedelai memiliki resiko keuangan yang kecil atau memiliki resiko kerugian yang kecil. Sehingga jika para petani atau pengusaha ingin mengajukan kredit ringan di Bank, maka akan memperoleh kemudahan pinjaman/kredit karena pihak perbankan akan lebih melihat rasio solvabilitas dari analisis rasio keuangan usahatani tersebut.

Demikian pula dengan hasil analisis Return on Investement atau ROI menunjukkan terjadi peningkatan yang siginificant terhadap persentasi kemampuan pengembalian modal awal/ investasi, sehingga usaha ini layak untuk dilanjutkan dalam jangka panjang. 
Tabel 5. Rasio Keuangan Usahatani Kedelai di Desa Puncak selama 3 tahun periode usaha

\begin{tabular}{lcccc}
\multicolumn{1}{c}{ URAIAN } & Tahun 0 & Tahun 1 & Tahun 2 & Tahun 3 \\
\hline Rasio Likuiditas & & & & \\
- Current Ratio & 125.6 & 514.7 & $1,126.6$ & NA \\
\hline Rasio Leverage (Solvabilitas) & & & & \\
- Debt to Asset Ratio & 69.1 & 19.5 & 9.4 & 0.0 \\
- Debt to Equity Ratio & 223.5 & 24.2 & 10.4 & 0.0 \\
\hline Rasio Profitabilitas & & & & \\
- Net Profit Margin & & 2.4 & 2.6 & 2.8 \\
- Return on Investment & & 65.7 & 71.2 & 76.6 \\
- Return on Equity & 93.9 & 16.5 & 15.3 \\
\hline
\end{tabular}

Ket. NA = Not Available (Nilai tak terdefinisikan).

\section{KESIMPULAN DAN SARAN}

\section{Kesimpulan}

1. Adaptasi kedelai varietas Tanggamus di Desa Puncak Kec. Pulubala sangat baik. Hal ini dibuktikan dengan perolehan hasil panen 2 kali lipat dari hasil deskripsi varietas, sehingga usahatani kedelai ini dapat mendatangkan keuntungan bersih sebesar Rp 7227600 per ha per musim.

2. Usahatani kedelai var.Tanggamus di Desa Puncak sangat layak untuk dilanjutkan dalam jangka panjang karena periode pengembalian modal hanya 9 bulan atau 2 musim tanam dengan Net B/C 2.64 dan IRR 97.21\% serta NPV (3 tahun) sebesar Rp 10269643.

\section{Saran}

1. Petani setempat sebaiknya terus melanjutkan kegiatan usahatani kedelai ini terutama varietas Tanggamus karena adaptasinya sudah baik dan harga jualnya pun tinggi karena mencapai Rp 6000 per kg.

2. Perlu ada kebijakan pengembangan wilayah kedelai di Kabupaten Gorontalo yang terpusat di Kecamatan Pulubala. Oleh sebab di wilayah tersebut umumnya petani banyak menanam tanaman jenis kacang-kacangan termasuk kedelai.

\section{DAFTAR PUSTAKA}

Balai Pengkajian Teknologi Pertanian Nusa Tenggara Barat. 2010. Petunjuk Teknik Pengelolaan Tanaman Terpadu (PTT) Kedelai. Balitbangtan, BPTP NTB, Mataram.

Choliq, H.R.A.R. Wirasasmita, S. Hasan, 1999. Evaluasi Proyek (Suatu Pengantar). Pionir Jaya, Bandung.

Doll, J.P. and Orazem, F. 1992. Production Economics : Theory with applications. Willey \& Sons Publ. New York.

Fajarwati, D. 2007. Analisis Cashflow (arus kas) sebagai Sumber Informasi bagi Serikat Pekerja di Wilayah Kabupaten/ Kota Bekasi. Jurnal Optimal, 1 (2) : 23 - 30.

Gittinger, J.P. 1986. Analisa Ekonomi ProyekProyek Pertanian. Terjemahan. Edisi Kedua. UI-Press dan John Hopkins, Jakarta.

Gray, C., Payaman, S., Lien K, P.F.L. Maspaitella, R.C.G., Varley. 1992. Pengantar Evaluasi Proyek. Edisi Kedua. Penerbit Gramedia, Jakarta.

Kusumawardani. 2002, Efisiensi Ekonomi Usahatani Kubis (Di Kecamatan Bumaji, Kabupaten Malang). Jurnal Agro Ekonomi (9) 1. Jurusan Sosial 
Ekonomi Pertanian Fakultas Pertanian UGM.

Nicholson, W. 2004. Intermediate Microeconomics and Its Application. Thomas Learning Publ.

Pusat Perpustakaan Badan Litbang Pertanian. 2008. Deskripsi Varietas Unggul Kedelai $\quad 1998 \quad-\quad 2008$. http://www.pustaka.litbang.deptan.go.i d. Diakses tanggal 21 November 2012.

Susantun I. 2000. Fungsi Keuntungan Cobb Douglas dalam Perdagangan Efisiensi Ekonomi Relatif. Jurnal Ekonomi Pembangunan, (5) $2: 149$ - 161 .

Soekartawi, A.Soeharjo, J.L.Dillon dan J.B.Hardaker. 1986. Ilmu Usahatani dan Penelitian untuk Pengembangan Petani Kecil. UI-Press, Jakarta.

Tahir, A. G., Darwanto, D. H., \& Mulyo, J. H. 2010. Analisis Efisiensi Produksi Sistem Usahatani Kedelai Di Sulawesi Selatan. Jurnal Agro Ekonomi, 28 (2) : $133-151$. 